\title{
A Comparison of Usability Aspects between an Existing Hospital Website of Pakistan with a Template based on Usability Standards
}

\author{
${ }^{1}$ Muhammad Usman, ${ }^{2}$ Mahmood Ashraf \\ Department of Computer Science \\ Federal Urdu University of Arts, Science \& Technology, \\ Islamabad, Pakistan
}

\author{
Muhammad Tahir \\ Faculty of Computing and Information Technology \\ University of Jeddah, \\ Jeddah, Saudi Arabia
}

\begin{abstract}
More people search internet for medical and health information. Due to increase in demand for online health services, hospitals need to equip their websites with usability standards. Hospital websites should be user centered in order to increase the usability. In the instant research study, an existing public sector hospital website is compared with a designed template for healthcare website. Template was designed keeping in view the user demands for hospital websites. Usability evaluation of both websites has been performed. Twenty-one users were involved in the research study. Three representative tasks were performed by each user on each website and a questionnaire was presented afterwards to collect user opinion about the websites under evaluation. Average score was calculated against both websites for each usability component. 75\% users responded positively to designed website template comparing with existing hospital website which got $33 \%$ positive responses only. Hence, it was evident that the designed template had better response for usability. The findings of this study justify the literature that user centered design can significantly improve usability of websites. This study is a step towards research which intends to understand usability problems and propose design rules for designing hospital websites of Pakistan in line with usability standards.
\end{abstract}

Keywords-Usability evaluation; healthcare website; hospital website evaluation

\section{INTRODUCTION}

The users are not satisfied with the health services and the number is increasing day by day [1]. More people search the internet for health information [2], [3]. A healthcare website can play a vital role in improving user satisfaction [4]. Users seems more satisfied with the availability of health information on the website of organization [5] but the quality of available information is not up to mark [6]. Usability is an important component for the successfulness of a website [7], [8]. User's involvement in the design can lead to developing more usable designs [9]. Hospital websites should be designed with the intent to address the users of all ages [10].

Despite the availability of number of health institutions, hospitals lag behind in providing online information [5]. The increased usage of internet for seeking medical information demands quality information [11]. Users turn towards hospitals when they feel satisfactory about their services [12] by searching for health related issues online [2], [13]. Therefore, hospitals need to provide satisfactory online services [2].

This research study intended to evaluate the usability of hospital websites. The study summarizes two prior studies and uses their finding to further understanding usability of hospital websites of Pakistan. Two user studies were performed to evaluate the private and public sector websites operational in Pakistan respectively prior to this study. Some design rules were formed in the previous user studies and users provided their specific requirements about the websites. User's expectations were recorded from earlier studies using questionnaire and direct observation methods and these provided bases for formulation of design rules. A website template on the basis of these design rules was designed including already existing guidelines for website development and a comparison was performed with an existing hospital website to interpret the usability.

The remaining part of the paper is described as: Section II shows the related work. Section III highlights the research methodology; experimental design, conduct of user study and procedure. Data analysis is discussed in Section IV. Section V reveals the results of research study. Discussion is done in Section VI and conclusion at the end.

\section{RELATED WORK}

Website usability evaluation is getting focus of researchers lately [14]. Usability is a quality attribute [15]. Website designed in accordance with usability standards can significantly improve the level of user satisfaction [16].

Internet is searched increasingly to find health-related information by older adults and their caretakers but the information is not accurate every time [2]. A web portal was designed and evaluated for usability in order to address the requirements of older adults. 37 users were involved in the usability study. Different methods of participation were used like in person testing, telephonic conversation, video conferencing. In $70 \%$ cases, participants were unable to complete a task. The researchers emphasized that involvement of end user in the design is important. It was difficult to search information on the website and the difficult language of contents was among the key findings. 
A research study was conducted by Raji, et al. (2013) to highlight the end user preferences on hospital websites inside Nigeria [11]. The study was focused on understanding the design features and contents in end user perspective. 100 participants in Group-A and another 100 in Group-B were involved in the study. Several themes were planned for testing the websites. The user responses were evaluated on the basis of usability heuristics. The researchers highlighted the importance of effective healthcare delivery system. The end users were unable to understand the instructions provided on the websites, however, they tend to prefer direct interaction.

People search the internet for medical problems, treatment and procedures [14]. The research investigated that the user expectations of patient oriented e-health tools on the hospital websites. 21 patient oriented e-health tools on the US hospitals websites were evaluated and 242 qualified participants were involved. The findings of research were that the websites lag behind the users' needs for interacting with hospital online. These findings can be applied to a hospital's planning to adopt e-health tools on their website. The paper concluded that the importance of understanding user's needs and preferences on the hospital websites cannot be neglected.

Gallant L et al. performed usability tests on teaching hospital in US using think-aloud collection protocol on 30 users. Usability test comprised of 34 tasks which were grouped in eight sections [5]. A user-centered design of hospital website was designed based on the user feedback. Collected data was analyzed using grounded theory approach. Users try to judge the trust, ease of use and usefulness as attributes of a hospital website were the key findings of the research. The researchers concluded that user-centered design in developing hospital website can become widely adopted.

A research study was developed to evaluate the website of healthcare institutions keeping in view the high demand of online health information [12]. Evaluation procedure was divided into three stages. The existing websites were evaluated against WCAG 2.0. The findings showed that proper procedures were not adopted while designing the websites. The accessibility of healthcare websites is poorly addressed which is misleading patients. Further findings depicted that people with disabilities were neglected in online designs which discourage their chances to be productive.

\section{METHOD}

\section{A. Design}

An existing hospital website in public sector of Pakistan was selected for evaluation along with website template designed on the basis of user responses collected in earlier studies and keeping in view user's expectations. This research study was centered to evaluate the websites as a comparison between existing (Fig. 1) and designed template (Fig. 2) in order to observer the user's understanding about these websites.

The study aimed on analysis of user data which was collected after performing representative tasks by each user and filling of post study questionnaire.

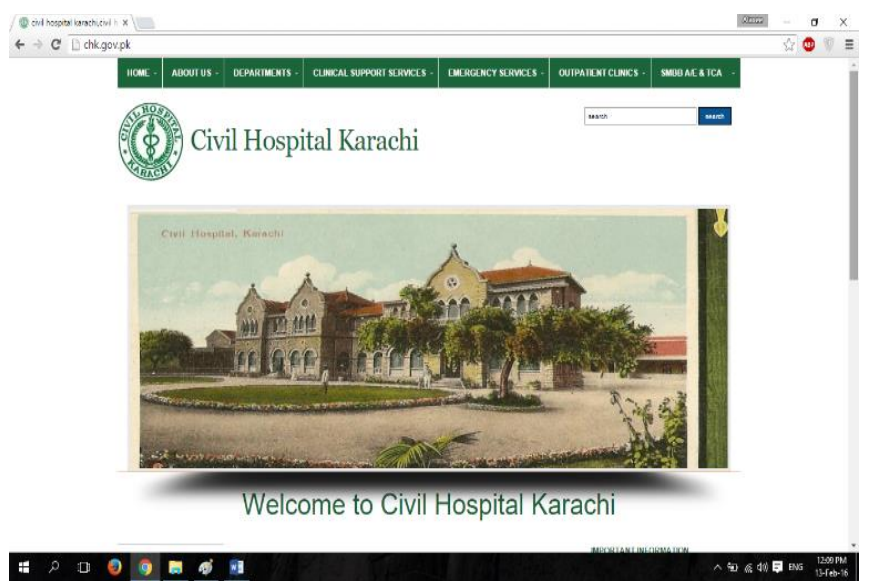

Fig. 1. Civil hospital, Karachi websites view.

Questionnaire and direct observation methods were adopted to record the usability of the websites.

A pre-study questionnaire was designed covering the consent of participant and their demographic details. The frequency of internet usage and purpose of usage was primarily focused in it. A query regarding already usage of any hospital website or not, was also included. Following representative tasks were chosen carefully keeping in view the user's common requirement for accessing the hospital website:

\section{1) Find the contact details of hospital \\ 2) Get the online appointment \\ 3) Locate the department of cardiology}

The tasks were of moderate nature to avoid the bar on user memory. A post-study questionnaire was designed based on five usability components (learnability, efficiency, memorability, error and satisfaction) developed by Nielsen [15]. An additional question for overall impression of the website design was also included in the questionnaire [17].

A five point Likert-scale was used [18], [19] for user compliance having ' 1 ' as 'strongly disagree' and ' 5 ' as 'strongly agree'.

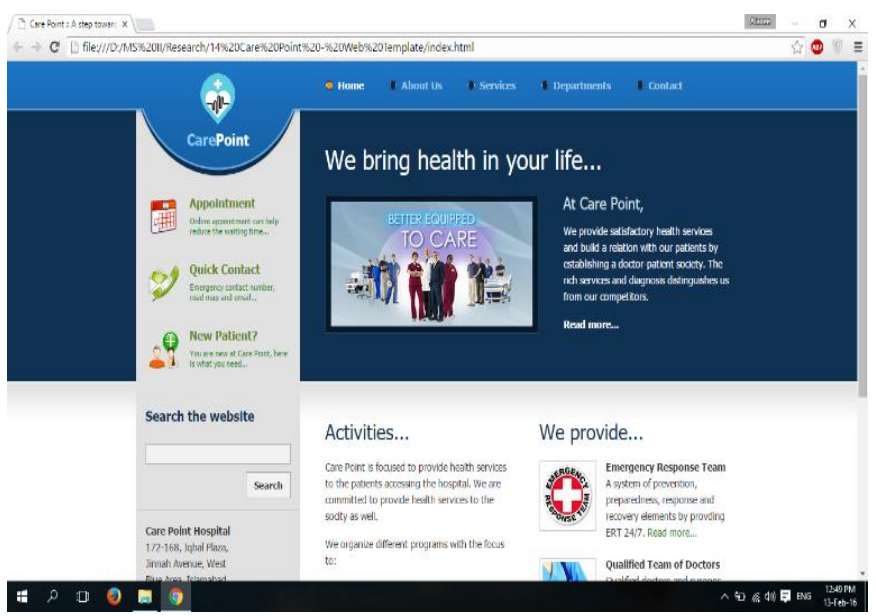

Fig. 2. Care point hospital websites template view. 
TABLE I. WEB USAGE FREQUENCY

\begin{tabular}{|l|l|l|}
\hline S \# & Description & Frequency \\
\hline 1 & Never & 0 \\
\hline 2 & Less than 3 years & 1 \\
\hline 4 & More than 2 years & 20 \\
\hline
\end{tabular}

TABLE II. AgE GROUP DIVISION OF PARTICIPANTS

\begin{tabular}{|l|l|l|}
\hline S \# & Description & Frequency \\
\hline 1 & Below 20 & 2 \\
\hline 2 & $21-30$ & 12 \\
\hline 3 & $31-40$ & 4 \\
\hline 4 & $41-50$ & 1 \\
\hline 5 & Above 50 & 2 \\
\hline
\end{tabular}

\section{B. Participants}

Twenty-one participants were involved in this empirical study. All the participants were volunteers. Different age group participants including male $(48 \%)$ and female $(52 \%)$ had parted in the study. Only one participant had web usage experience less than three years, rest had more than three years' experience (Table I). Fourteen participants (67\%) had already used the hospital website. However, seven participants (33\%) were using any hospital website for the first time.

Most of the participants $(48 \%)$ were among the age group of 21-30 (Table II). Two participants were each from below 20 age group and above 50 years. Four (19\%) users were from 3140 age group and only one user had age group 40-50.

\section{Experimental Design}

A consent form containing demographic details was presented to the participant for collecting basic information. Representative tasks were chosen to be performed by participants. All the participants were volunteers of different ages and professional levels. The users were observed from behind when they were performing the tasks.

Questionnaire and observation methods were adopted. 20minute time was planned for each participant to perform the tasks. Participants performed the tasks well within time. Websites were already open in the web browser. While performing the tasks, participants were free to ask about the tasks and websites. After completion of tasks, a post-study questionnaire was presented to the user.

\section{Procedure}

Participants were approached at their convenient locations in most of the cases. However, some of them were invited in FUUAST labs for conducting the study. Participants were observed from behind while performing tasks. Some participants were photographed from behind as well after their consent (Fig. 3).

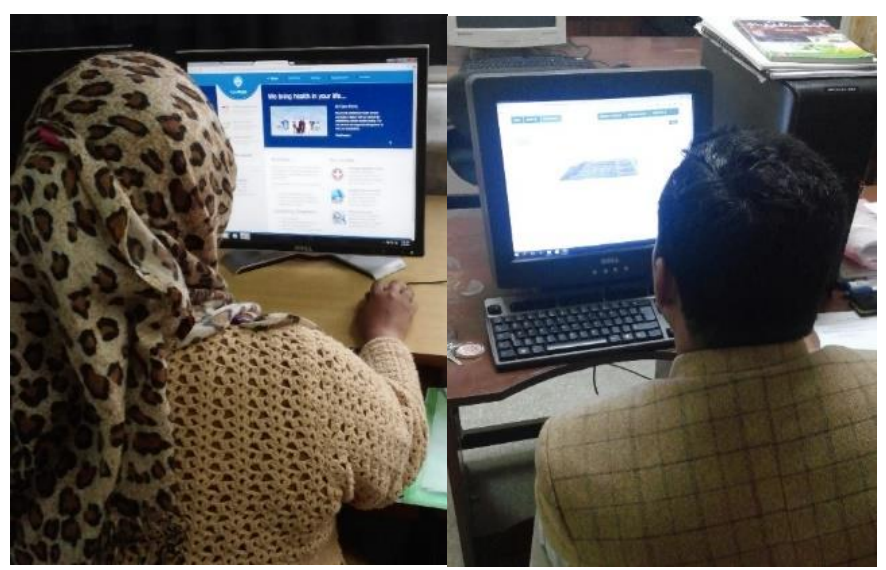

Fig. 3. Users performing tasks during user study.

When the participant declared about completion of tasks, they were presented the post study questionnaire. Participants were briefed about the questions on their demand.

\section{DATA ANALYSIS}

Likert-Scale values for each website have been recorded against each usability component (Tables III and IV).

The average results showed that the participants selected "Strongly Agree" (75\%) from Likert-Scale in most of the cases for Care Point Hospital Website Template (Fig. 4). However, $37 \%$ of the responses were "Disagree" and another $22 \%$ "Strongly Disagree" for usability of Karachi Civil Hospital Website, on the other hand. User tasks were performed on the Civil Hospital Karachi website before performing them on the Care Point Hospital Website template.

TABLE III. AvERAgE SCORE OF CIVIL HoSPITAL KARACHI

\begin{tabular}{|l|l|l|l|l|l|l|}
\hline \multirow{2}{*}{ S \# } & \multirow{2}{*}{ Questions } & \multicolumn{3}{|l|}{ User Responses } \\
\cline { 3 - 7 } & & 1 & 2 & 3 & 4 & 5 \\
\hline 1 & $\begin{array}{l}\text { Is it easy to use } \\
\text { the website? }\end{array}$ & 9 & 9 & 2 & 1 & 0 \\
\hline 2 & $\begin{array}{l}\text { I learned to use it } \\
\text { quickly? }\end{array}$ & 8 & 9 & 2 & 1 & 1 \\
\hline 3 & $\begin{array}{l}\text { It is easy to } \\
\text { remember how to } \\
\text { use the website? }\end{array}$ & 6 & 5 & 4 & 5 & 1 \\
\hline 4 & $\begin{array}{l}\text { Have you found } \\
\text { any mistake in } \\
\text { the system while } \\
\text { performing the } \\
\text { tasks? }\end{array}$ & 2 & 6 & 5 & 4 & 3 \\
\hline 4.1 & $\begin{array}{l}\text { If so, how easy it } \\
\text { is for you to } \\
\text { recover from } \\
\text { them? }\end{array}$ & 0 & 8 & 3 & 5 & 5 \\
\hline 5 & $\begin{array}{l}\text { It is pleasant to } \\
\text { use? }\end{array}$ & 4 & 10 & 3 & 4 & 0 \\
\hline 6 & $\begin{array}{l}\text { The design of the } \\
\text { website is } \\
\text { beautiful? }\end{array}$ & 4 & 7 & 5 & 5 & 0 \\
\hline
\end{tabular}


TABLE IV. Average SCORE of Care Point Hospital Template

\begin{tabular}{|l|l|l|l|l|l|l|}
\hline \multirow{2}{*}{ S \# } & Questions & \multicolumn{3}{|l|}{ User Responses } \\
\cline { 3 - 7 } 1 & $\mathbf{1}$ & $\mathbf{2}$ & $\mathbf{3}$ & $\mathbf{4}$ & $\mathbf{5}$ \\
\hline 2 & $\begin{array}{l}\text { Is it easy to use } \\
\text { the website? }\end{array}$ & 0 & 0 & 0 & 5 & 16 \\
\hline 3 & $\begin{array}{l}\text { I learned to use it } \\
\text { quickly? }\end{array}$ & 0 & 0 & 0 & 5 & 16 \\
\hline 3 & $\begin{array}{l}\text { It is easy to } \\
\text { remember how to } \\
\text { use the website? }\end{array}$ & 0 & 1 & 0 & 7 & 13 \\
\hline 4 & $\begin{array}{l}\text { Have you found } \\
\text { any mistake in } \\
\text { the system while } \\
\text { performing the } \\
\text { tasks? }\end{array}$ & 0 & 0 & 0 & 1 & 20 \\
\hline 4.1 & $\begin{array}{l}\text { If so, how easy it } \\
\text { is for you to } \\
\text { recover from } \\
\text { them? }\end{array}$ & 0 & 0 & 1 & 1 & 19 \\
\hline 5 & $\begin{array}{l}\text { It is pleasant to } \\
\text { use? }\end{array}$ & 0 & 0 & 2 & 4 & 15 \\
\hline 6 & $\begin{array}{l}\text { The design of the } \\
\text { website is } \\
\text { beautiful? }\end{array}$ & 0 & 0 & 4 & 6 & 11 \\
\hline
\end{tabular}

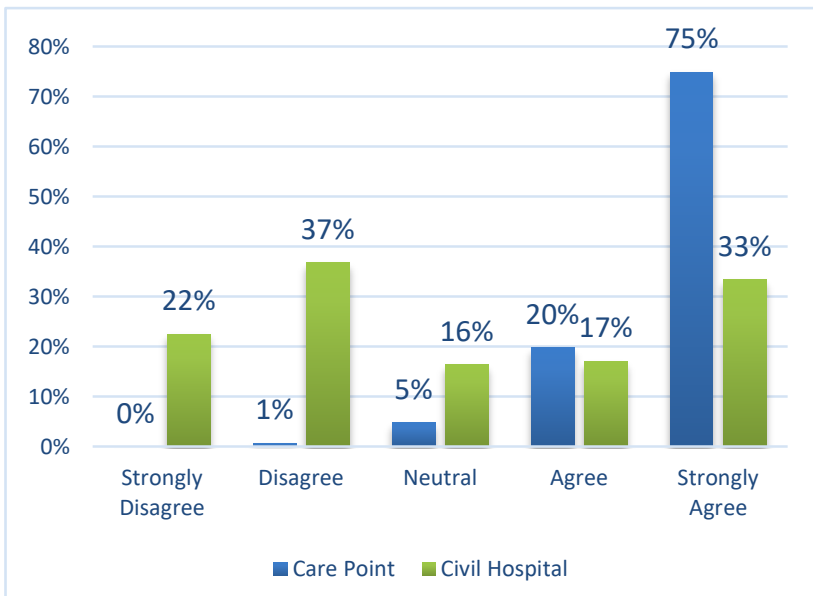

Fig. 4. Average Likert-scale selection in post study questionnaire.

In $95 \%$ cases (20 out of 21 ), users performed tasks without committing or facing any error on Care Point Hospital website. On the other hand, participants faced hardships in performing the tasks on Civil Hospital Karachi website as was recorded in the response in Table III.

\section{RESULTS}

The overall results showed (Fig. 4) that the user's responses were positively inclined towards the Care Point Hospital (CPH) Website (Template) in terms of usability. As many as $75 \%$ of the participants "strongly agreed" and another $20 \%$ "agreed" with the usability aspects of the proposed design template comparing with Civil Karachi Hospital (CHK) Website for which $22 \%$ "strongly disagreed" and $37 \%$ "disagree" responses were recorded. Only $1 \%$ responses were "disagree" and none of the participants marked "strongly disagree" for the CPH template.

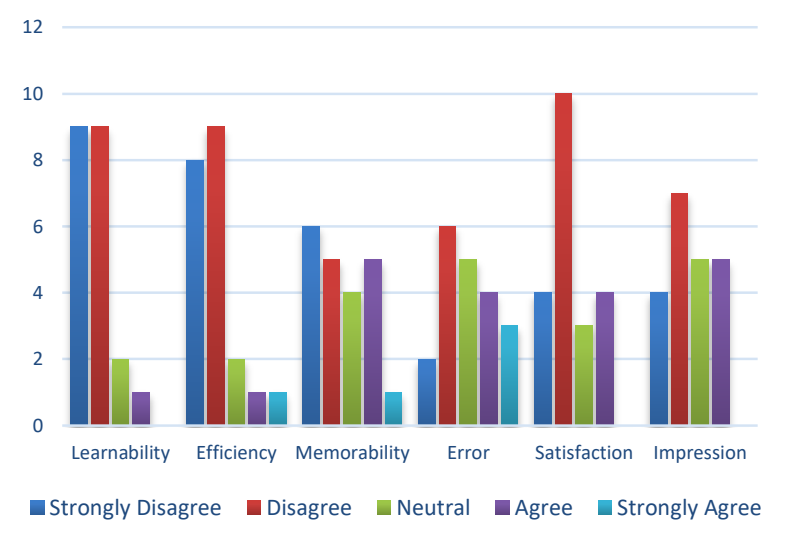

Fig. 5. Responses of participants for Civil Hospital Karachi.

For CPH template 5\% responses were neutral and similarly $16 \%$ users remained neutral for $\mathrm{CHK}$ website. Fig. 5 portrays the user response towards CHK separately and Fig. 6 depicts the results of $\mathrm{CPH}$ template only.

The usability components have been evaluated as follows:

\section{A. Learnability}

$43 \%$ users responded each in "Strongly Disagree" and "Disagree" for CHK website. 10\% users remained "Neutral" about their views and only 5\% "Agreed" with the learnability of the CHK website. On the contrary, 76\% user "Strongly Agreed" and 24\% "Agreed" with the usability aspects of CPH website template.

\section{B. Efficiency}

$38 \%$ and $43 \%$ responses were "Strongly Disagree" and "Disagree" for CHK respectively. 10\% neutral views and 5\% each for "Agree" and "Strongly Agree". 76\% and 24\% users "Strongly Agreed" and "Agreed", respectively for $\mathrm{CPH}$ website template.

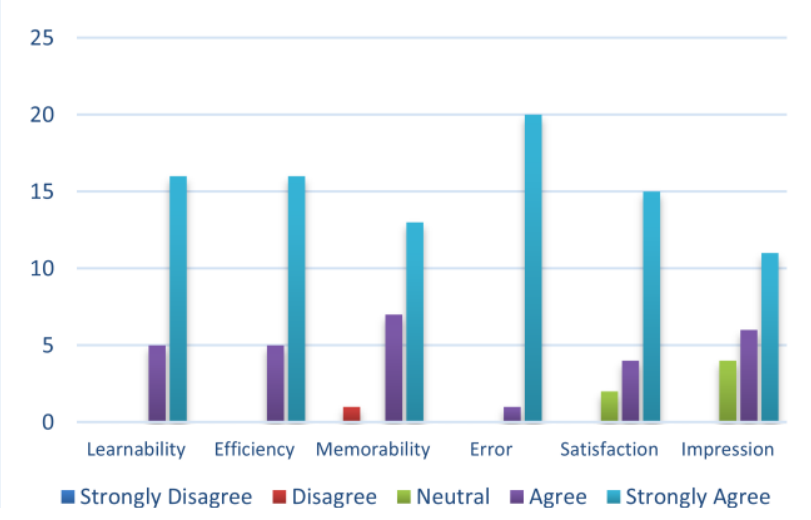

Fig. 6. Responses of participants for Care Point Hospital Website Template.

\section{Memorability}

$29 \%$ users "Strongly Disagree" with the memorability of the CHK website. Another 24\% "Disagree" and 19\% "Neutral" responses were received. 24\% "Agreed" with this component 
and 5\% rated "Strongly Agree" in case of CHK website. For $\mathrm{CPH}$ template, $62 \%$ users "Strongly Agree" with the memorability component of usability and 33\% had "Agree" response. Only 5\% (one instance) "Disagree" with it.

\section{Error}

95\% users did not commit any error while performing tasks on $\mathrm{CPH}$ website template. On the other hand, $10 \%$ users committed many mistakes while using CHK website. $29 \%$ and $24 \%$ users marked error rate as " 5 or 4 " mistakes, respectively. $19 \%$ committed two mistakes and $14 \%$ committed single mistake.

\section{E. Satisfaction}

$19 \%$ users remained fully unsatisfied with the CHK website as shown in Fig. 5. However, $48 \%$ responses were "Disagree". $14 \%$ "Neutral" remarks and 19\% were "Agree" responses while $71 \%$ users showed their full satisfaction for $\mathrm{CPH}$ template. $19 \%$ responded with "Agree" to their satisfaction level and $10 \%$ had "Neutral" views.

\section{F. Impression}

$52 \%$ participants appreciated the overall design of $\mathrm{CPH}$ website template by showing "Strongly Agree" response (Fig. 6). Another 29\% showed "Agree" views. 19\% had "Neutral" remarks. 19\% users did not appreciate the design and responded with "Strongly Agree" for CHK website. 33\% users had "Disagree" remarks and 24\% were "Neutral". Another $24 \%$ users had "Agree" response.

The user responses recorded in Tables III and IV have been statistically analyzed afterwards. Paired sample t-test was applied to the data using SPSS. Care Point Hospital (CPH) website template has been assigned $\mu 1$ and Civil Hospital Karachi (CHK) website has been assigned $\mu 2$. The standard deviation has been calculated as 11.1034 and value of $t$ was derived as $t=17.6024$. As the value of $t$ is very high therefore we reject null hypothesis and hence conclude that $\mathrm{CPH}$ website template is more usable than $\mathrm{CHK}$ website.

\section{DISCUSSION}

The Website Template was designed keeping in view the user's opinion and responses received from participants in User Study 1 and User Study 2. The template was named Care Point Hospital Website Template. The responses of users in earlier studies were observed and analyzed carefully hence the guidelines so proposed have been utilized in development of template. The template is based on user's requirements and approaches towards usage of hospital websites. The guidelines proposed in User Study 1 and 2 were the theme behind the design and development of template. However, more design rules and user expectations were also considered before designing the template.

The design rules such as participants suggested in earlier user studies that a website should have a search option, in case user is unable to locate specific information from the website. This will help to extract and locate such information immediately were followed in the template design.

The font face, size and color were also focused as was highlighted in the former user studies by users. The contrast of the fonts comparing with the background color was also vital in design. A hospital website poorly managed in this way has a weakened usability as was analyzed in user studies performed previously.

The important options for accessing information on the website is designed and spread in accordance with the FShaped Pattern for Reading Web Content [20]. The template so designed was evaluated in contrast to existing hospital website. The existing hospital website had negative usability; however, the design template had higher usability responses. Hence the results were clear. Users responded that the Care Point Hospital Websites (Template) has been more useable than the other one which has negative usability.

\section{CONCLUSION}

Hospitals are a source of healthy society not only by providing health services but keeping their patients aware about health in particular and spreading health tips to common people in general. This aspect is more significant in Pakistan as Pakistan is a developing country where health institutions and hospitals can improve the system by playing their part. A vision of healthier society can be achieved through a system having affordable, efficient, technology appropriate and consumer friendly. A website having such features can significantly straighten the road towards goal.

A website designed by keeping in view the usability aspects can result into more satisfied users. The template under evaluation was designed in accordance with the expectation of users hence the satisfaction level of the users raised which clearly indicated in highly useable website.

This study is part of the research that intends to propose design rules for hospital websites of Pakistan. The outcome of this research will become part of planned design rules.

\section{REFERENCES}

[1] Dos Anjos, T.P., et al., Usability Evaluations of Health Institutions Inspection Software. IEEE Latin America Transactions, 2016. 14(3): p. 1538-1547

[2] Barbara, A.M., et al., The McMaster Optimal Aging Portal: Usability Evaluation of a Unique Evidence-Based Health Information Website. JMIR human factors, 2016. 3(1).

[3] Johnson, M.A. and K. Norris Martin, When Navigation Trumps Visual Dynamism: Hospital Website Usability and Credibility. Journal of Promotion Management, 2014. 20(5): p. 666-687.

[4] Raji, S., et al., Usability Evaluation of Hospital Websites in Nigeria: What Affects End Users' Preferences?, in HCI International 2014 Posters' Extended Abstracts, C. Stephanidis, Editor. 2014, Springer International Publishing. p. 430-434.

[5] Gallant, L., C. Irizarry, and G.L. Kreps, User-centric hospital web sites: a case for trust and personalization. E-service Journal, 2007. 5(2): p. 5-26.

[6] Allam, A., P.J. Schulz, and K. Nakamoto, The impact of search engine selection and sorting criteria on vaccination beliefs and attitudes: two experiments manipulating Google output. Journal of medical Internet research, 2014. 16(4): p. e100.

[7] Abdullah, R. and K.T. Wei, Usability measurement of Malaysia online news websites. International Journal of Computer Science and Network Security, 2008. 8(5): p. 159-165.

[8] Kaur, S., K. Kaur, and P. Kaur. Analysis of website usability evaluation methods. in Computing for Sustainable Global Development (INDIACom), 2016 3rd International Conference on. 2016. IEEE. 
[9] Abras, C., D. Maloney-Krichmar, and J. Preece, User-centered design. Bainbridge, W. Encyclopedia of Human-Computer Interaction. Thousand Oaks: Sage Publications, 2004. 37(4): p. 445-456.

[10] Fink, A. and J.C. Beck, Developing and Evaluating a Website to Guide Older Adults in Their Health Information Searches A Mixed-Methods Approach. Journal of Applied Gerontology, 2015. 34(5): p. 633-651.

[11] Raji, S.O., M. Mahmud, and A. Abubakr, Evaluation of University Teaching Hospital Websites in Nigeria. Procedia Technology, 2013. 9: p. 1058-1064.

[12] Martins, J., et al., How Ill Is Online Health Care? An Overview on the Iberia Peninsula Health Care Institutions Websites Accessibility Levels, in New Advances in Information Systems and Technologies. 2016, Springer. p. 391-400.

[13] Huerta, T.R., D.M. Walker, and E.W. Ford, An Evaluation and Ranking of Children's Hospital Websites in the United States. Journal of Medical Internet Research, 2016. 18(8).
[14] Huang, E., C.-c. Angela Chang, and P. Khurana, Users' preferred interactive e-health tools on hospital web sites. International Journal of Pharmaceutical and Healthcare Marketing, 2012. 6(3): p. 215-229.

[15] Nielsen, J., Usability engineering. 1994: Elsevier.

[16] Yadrich, D.M., et al., Creating patient and family education web sites: assuring accessibility and usability standards. Comput Inform Nurs, 2012. 30(1): p. 46-54.

[17] Wynn, L. and J. Trussell, The morning after on the internet: usage of and questions to the emergency contraception website. Contraception, 2005. 72(1): p. 5-13.

[18] Norman, G., Likert scales, levels of measurement and the "laws" of statistics. Advances in health sciences education, 2010. 15(5): p. 625-632.

[19] Scales, L.-T., Analyzing and Interpreting Data From. Journal of graduate medical education, 2013: p. 541.

[20] Nielsen, J. (2006). " F-Shaped Pattern For Reading Web Content," Jakob Nielsen's Alertbox. http://www.useit.com/alertbox/reading_pattern. html. 